Asomarseporla ventana, un viaje a la luna

\section{Literatura infantil}

\section{Karla Carreón}

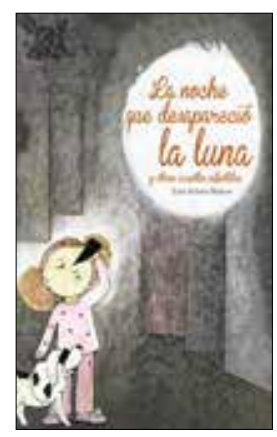

Luis Arturo Ramos,

La noche que desapareció la luna y otros cuentos infantiles, Xalapa, Instituto Literario de Veracruz/Secretaría de Cultura-DGP, 2017, 171 pp.

olo la mirada infantil es productora de nostalgia. En $\mathrm{La}$ noche que desapareció la luna $y$ otros cuentos infantiles, Luis Arturo Ramos invita a lectores de todas las edades a compartir este mismo hilván, el hilo de Ariadna que nos devuelve el sentido de extrañeza ante un mundo nuevo, y la añoranza de algo que se ha extraviado en él. Lo difícil es no saber qué, cómo ocurrió tal pérdida. Lo encantador: la esperanza de recuperarlo. Esta colección, publicada a finales de 2017 por el Instituto Literario de Veracruz en coedición con la Secretaría de Cultura, nos permite rescatar el interés que ha mostrado su autor desde hace un par de décadas por tal mirada.

Son seis los cuentos que la componen: "Zili el unicornio", "La noche que desapareció la luna.
Cuento para contar en la noche", "Coatl. La voz de la tierra", "Telésforo, el teléfono desocupado", "Blanca-Pluma" y "Un tucán llamado Noé”. En ellos, la maravilla que parecía abandonada en algún cuento de antaño en que el dragón y la victoria sobre él marcaban el fin de una aventura, es resignificada para formar parte de los ritmos vertiginosos del mundo actual. Cada cuento desarrolla la particularidad de su maravilla, porque es justo lo que se encargan de narrar, una maravilla reconfigurada, moderna.

La narrativa de Luis Arturo Ramos dedicada al público infantil muchas veces pasa desapercibida, $y$ por primera vez se realiza una recopilación que conjuga todos los títulos de esta categoría. Ramos nos regaló a lo largo de varias décadas un significativo número de ellos, dejando con el tiempo una estela presidida por su primera publicación, Zili el unicornio, cuento que se asoma en el cosmos literario en 1980 por la Editorial de la Universidad Veracruzana en coedición con el Fondo Nacional para Actividades Sociales (Fonapas).

Si entendemos al libro como el límite físico entre los textos, sus obras infantiles se hallan lejanas unas de otras tanto física como temporalmente en este firmamento. Después de esta primera propuesta todos los cuentos incluidos en la colección de 2017 conocieron a sus primeros lectores en diferentes años y variadas casas editoriales: La noche que desapareció la luna (1982, Editorial Práctica de Vuelo); La voz de Coatl (1983, Editorial Novaro); Blanca Pluma (1993, Editorial Grijalbo); Un tucán llamado Noé (2000, Colección Agua Clara, Ivec/Conaculta) y Telésforo, el teléfono desocupado (2013, Instituto Literario de Veracruz). ${ }^{1}$ Por otro lado, el autor minatitleco también cuenta con títulos que com- pilan dos o más cuentos, como Cuentiario (1986, Editorial Amaquemecan), que incluye "Zili el unicornio" y "Telésforo el teléfono desocupado" con ilustraciones de Antonio Helguera, y La noche en que desapareció la luna (2000, Editora de Gobierno del Estado de Veracruz), que contiene "Zili el unicornio", "La noche en que desapareció la luna", "Coatl" y "Telésforo el teléfono desocupado", ilustrados por Leticia Tarragó.

La relevancia de La noche que desapareció la luna y otros cuentos infantiles radica en el trabajo editorial que implica unir todo este universo literario de Luis Arturo Ramos. Hay una evolución que vale la pena revisar respecto a las diferentes ediciones bajo este título. La de La noche que desapareció la luna de 1982 por la Editorial Práctica de Vuelo se ajusta al formato de bolsillo y cuenta con solo tres ilustraciones en blanco y negro de Luis Fernando Enríquez Rocha. Ya para el 2000, la compilación de La noche que desapareció la luna de la Editora de Gobierno del Estado de Veracruz incluiría por primera vez las ilustraciones de Leticia Tarragó, también en blanco y negro. Este último título, ofrece a sus lectores 15 ilustraciones de la artista plástica veracruzana, las cuales adquieren mayor trascendencia en su impresión al abarcar la página completa del pequeño formato.

A diferencia de ambas publicaciones previas, esta última colección de 2017 apuesta por renovar la lectura de los cuentos de Ramos por medio de una transformación estética que reviste por primera vez con colores a sus personajes de antaño, jugando con una paleta que resulta atractiva para los lectores e incorporando, además de las ilustraciones de Tarragó, las de Iván Flores Hernández y Rafael Antúnez Piña. Lo anterior, así como la evolución del 
La palabra "lunático" proviene del latín lunaticus, referido a la creencia de la estrecha relación entre las conductas vesánicas y la luna llena.

nos maravillamos al asomarnos a aquella ventana conformada por palabras, la misma a la que se asoman los personajes de Luis Arturo Ramos, en la que, muchas veces, avistábamos ese pasado de ojos bien abiertos y asombrados.

Por otro lado, "La noche que desapareció la luna” narra la huida de este satélite, acechado por un ente mecánico, un monstruo llamado Kohetón. La noche y la luna, sustantivos que forman parte del título de la publicación, integran una metáfora y una reflexión que valen la pena sugerir: ¿Qué pasaría si, una noche, la luna se pierde? Mariana y Ferdinand, dos personajes cuyas aventuras los han consagrado expertos en situaciones extrañas, son ahora sorprendidos por lo insólito, con lo sumamente improbable, pues ¿acaso puede haber una oscuridad mayor que la misma noche? En este cuento, la luz de la luna se va "como si todo mundo hubiera cerrado los ojos", es decir, de un momento para otro, y sobre todo, porque la noche por sí misma es el espacio en que todo es posible, en que, desde el instante minúsculo de un cerrar de ojos, accedemos a esa otra noche perceptible solo por la mirada infantil de sus protagonistas.

En un cerrar y abrir de ojos, aquello que damos por sentado puede desaparecer o bien, huir. La luna es un personaje que intriga al lector puesto que se halla aquí fuera de sus dominios, indefensa en una ciudad extraña. Mariana y Ferdinand no saben a ciencia cierta qué es lo que la persigue, ni para qué, pero saben que es su deber ayudarla. Sobresalen en este cuento las ilustraciones de Leticia Tarragó, pues incitan a formar parte de la oscuridad como testigos medulares. Mientras que los personajes deben usar diversos medios para observar a su asustadiza interlocutora, Tarragó nos muestra de manera detallada lo que estos aventureros no pueden percibir: la luna no es más que una niña de cabellos largos con una mirada profunda y etérea. Solo nosotros, los lectores, podemos contemplar esta luna angelical a pesar de su luz cegadora.

Así como los anteriores, los demás personajes se manifiestan ante nosotros ansiosos por llevar a cabo la aventura, siempre asequible por medio del sueño, la imaginación y lo maravilloso. Mediante la empatía hacia éstos, Luis Arturo Ramos concede a sus lectores dos posibilidades: por un lado, la reflexión acerca del presente a través de su relación con un pasado más próspero; por el otro, un reencuentro con la nostalgia por diferentes valores transgredidos por la modernidad, como las tradiciones, la identidad, las cosmogonías, la cultura y la ecología.

La palabra "lunático" proviene del latín lunaticus, referido a la creencia de la estrecha relación entre las conductas vesánicas y la luna llena. ¿Qué nos querrá decir entonces Ramos si la luna huye de la bóveda celeste para refugiarse muy cerca de nuestra ventana? LPyH

\section{Nota}

${ }^{1}$ Este título también fue publicado por la serie Pasos de Luna de Libros del Rincón de la Secretaría de Educación Pública (SEP).

Karla Carreón es maestra en Literatura Mexicana por la Uv. Es autora de Momoto y coautora de Cosecha de Letras.

\section{Entre homena- jes: El complot mongol}

Novela ġráfica

Yuliana Rivera

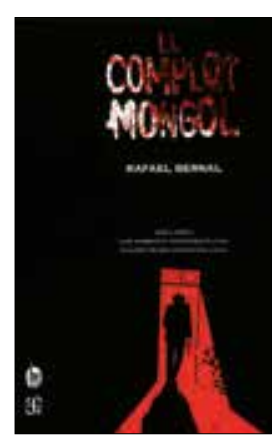

Rafael Bernal,

El complot mongol, guion de Luis Humberto Crosthwaite, dibs. de Ricardo Peláez, México, FCE/Joaquín Mortiz, 2017, 120 pp.

casi cuarenta años de su primera edición, el Fondo de Cultura Económica junto con Joaquín Mortiz, editor de la versión original (1969), publican en el formato de novela gráfica El complot mongol, un clásico de la literatura mexicana. El guion de esta versión es de Luis Humberto Crosthwaite (Tijuana, 1962), y los dibujos, de Ricardo Peláez Goycochea (Ciudad de México, 1968), de modo que cuando tuve la primicia de su publicación -vía la cuenta de Facebook del guionista-, no dudé en adquirirla.

En la pasada FILU 2018 en Xalapa, Ver., conversé con el ilustrador de la novela, quien me contó las vicisitudes por las que pasó la publicación de este trabajo: las mudanzas del proyecto de una casa editorial a otra debido a los derechos de autor, el formato a color y el tema de la novela; todo ello ha- 